\title{
Simulation of Precooling Strategies in Office Buildings: Deriving Demand Side Management Potentials
}

\author{
Jonas Müller $^{1}$, Martin Meyer ${ }^{1}$, Ulrich Reiter ${ }^{1}$, Martin Jakob ${ }^{1}$ \\ ${ }^{1}$ TEP Energy GmbH, Zurich, Switzerland
}

\begin{abstract}
Currently, load profile simulations for cooling loads in buildings are focusing on very specific subsets of temperature profiles and locations. This study aims to broaden the picture and to evaluate several load shifting (LS) strategies and compare them to the electrical load of conventional cooling during peak hours. Additionally, indoor temperature and load profiles of different service sector buildings (light and heavy mass buildings) are simulated for different LS strategies. Results are calculated by means of the building simulation software IDA ICE. Simulations for different locations in Europe will demonstrate the shifting potential under differing climate conditions.
\end{abstract}

\section{Introduction}

Increasing internal loads, rising comfort standards, or warmer climate lead to an increasing cooling energy demand in buildings (Connolly, 2017). Maximum cooling loads for air conditioning are often concentrated around the hottest hours of the day, correlating with peak electricity demand from other appliances or drivers, especially the high occupation rate in office buildings in the afternoons. The extra amount of electricity during peak hours is commonly satisfied by power plants with high marginal cost and respective $\mathrm{CO}_{2}$ emissions. This results in higher generation costs for the electricity utility and consequently for the consumers (Turner, Walker, \& Roux, 2015). Thus, shifting cooling loads by demand side management (DSM) to off-peak hours is beneficial for electric utilities and reduces the strain on the electric grid. Moreover, electricity consumers benefit from lower energy prices at off-peak hours (German, Hoeschele, Springer, \& Others, 2014). Therefore, to reduce cooling demand at peak time, precooling might be a promising strategy to shift cooling loads from peak to off-peak hours by guaranteeing required comfort levels.

Alternatively, anticipating increasing renewable generation in the future, the utilization of wind or solar power is partially limited by their variable and intermittent character (Amusat, Shearing, \& Fraga, 2018). However, since highest photovoltaic (PV) production is at noon just before cooling load peaks, LS strategies could also prove as a solution to compensate for the peak generation of renewables (German et al., 2014). Additionally, one LS strategy includes the use of the buildings thermal mass, and therefore the ability of a material to store heat or cold. Thermal mass enables the building to flatten out the thermal energy flows as a response to the fluctuating ambient temperature (Rongxin, 2015). Thus, specific building envelope properties allow to store thermal energy and consequently reducing peak loads.

The building mass storage is also relevant in terms of cooling storage design. Notably, cooling storages typically exhibit smaller temperature differences between supply and return temperature and do not include phase changes. Therefore, the tank volume of a cooling storage needs to be bigger dimensioned and would further increase costs.

Several studies investigated the DSM and LS potential in office buildings, mostly for hot climate regions. Usually one building type in a specific climate zone was defined and simulated over a short period of time. Rongxin (2015) conducted a case study about precooling of a medium-mass office building in California and further demonstrate two approaches to model thermal mass. Xu, Haves, Piette, \& Braun (2004) conducted a test study for a medium-sized office building in California. Two precooling strategies were tested during October and showed significant peak demand savings. Yang \& Li (2008) demonstrated a building model for office buildings to study the relationship between thermal mass and cooling load. Their results showed that mostly buildings with an appropriate size of thermal mass in suitable climate conditions will benefit. Ma, Qin, Salsbury, \& Xu (2012) developed a predictive control strategy for building energy demand reduction. Cui, Wang, Yan, \& Xue (2015) developed a control strategy to immediately shut down chillers if requested by the operator.

Different precooling strategies with a focus on residential buildings with low thermal mass were evaluated by Turner et al. (2015). They concluded that precooling increases the annual cooling load, but reduces the peak cooling load. However, there are limited comprehensive studies regarding the cooling demand profile and LS considering several cooling strategies in different office buildings or locations.

Hence, the aim of this study is to compare several precooling strategies for different building typologies and get insights into the LS potential for office buildings which is used as input to general load profile models 
such as eLOAD (Jakob, Kallio, \& Bossmann, 2014) in the context of (TU Dresden, 2016). Therefore, simulation runs for three different types of office buildings with several cooling strategies are conducted. Indoor temperature and load profiles of different service sector buildings (light and heavy mass buildings) are simulated for different LS strategies by means of the building performance simulation software IDA Internal Climate and Energy (ICE). Thus, the impact of different physical properties of the buildings on cooling demand and LS potentials are evaluated. Additionally, the simulations are conducted at three differing locations in Europe to demonstrate the LS potential in different climate regions.

The holistic approach used in this work provides insights into building specific prospects (e.g. thermal mass) to shift cooling loads. Second, the approach enables a comparison of the LS potential for cooling loads between different climate zones. Further, it shows, which of the LS strategies can meet reasonable indoor climate comfort conditions. Besides shifting peak loads and saving cooling energy, it is essential to meet reasonable comfort conditions for occupants. Precooling of office buildings with a temperature reset in the morning hours follows the ambient temperature and thus enables reasonable comfort conditions for employees and customers in the building.

Depending on the daily climatic condition and shortterm future temperature changes, as well as on the electricity price signal from the grid, one of the investigated LS strategies has to be applied. However, in this work, we focus on the building related LS potential and the respective strategies.

\section{Method}

By means of the building performance simulation software IDA-ICE, five typical single office rooms (zones) in a multi-story building were modelled at three different geographical locations. The thermal cooling load and indoor temperatures were simulated by the software with dynamic time steps and hourly outputs. Therewith, a comparison between the cooling strategies and the building-envelope properties as well as the location were conducted. Each zone is equipped with an ideal cooler which does not have any physical location within the room but is an accurate approximation to determine the thermal cooling load of a zone. The capacities of the coolers are sufficiently oversized in order to satisfy thermal comfort under all conditions. Air handling units (AHU) are modelled for new buildings with respective air flows and inlet / outlet air temperatures.

\section{Building specific properties}

Two new buildings (BN1 and BN2) as well as an old building (BB3) with different building properties are considered for the simulations. The construction type, window share and U-value of the corresponding building are presented in Table 1.
Table 1: Overview of simulated building types BN1, BN2 and BB3 with corresponding properties (construction, window share and U-value).

\begin{tabular}{|c|c|c|c|}
\hline $\begin{array}{c}\text { Building } \\
\text { Type }\end{array}$ & Construction & $\begin{array}{c}\text { Window share } \\
{[\% \text { of total }} \\
\text { facade area] }\end{array}$ & $\begin{array}{c}\mathbf{U} \text {-value } \\
{\left[\mathbf{W} /\left(\mathbf{m}^{\mathbf{2}} \mathbf{K}\right)\right]}\end{array}$ \\
\hline BN1 & Light mass & 60 & 0.57 \\
\hline BN2 & Heavy mass & 50 & 0.44 \\
\hline BB3 & Heavy mass & 35 & 1.23 \\
\hline
\end{tabular}

Week-daily time schedules are defined for all relevant internal heat loads (i.e. lighting, occupation and equipment depicted in yellow, blue and red, respectively; cf. Figure 1) and losses (e.g. AHU or air tightness). The load factors (LF) represent the ratio between the actual and the full load of the corresponding parameter. The LF for occupants drops at midday, when people leave the office for lunch. For light and equipment, loads remain high for the full day. On Saturday and Sunday, no internal loads are assumed.

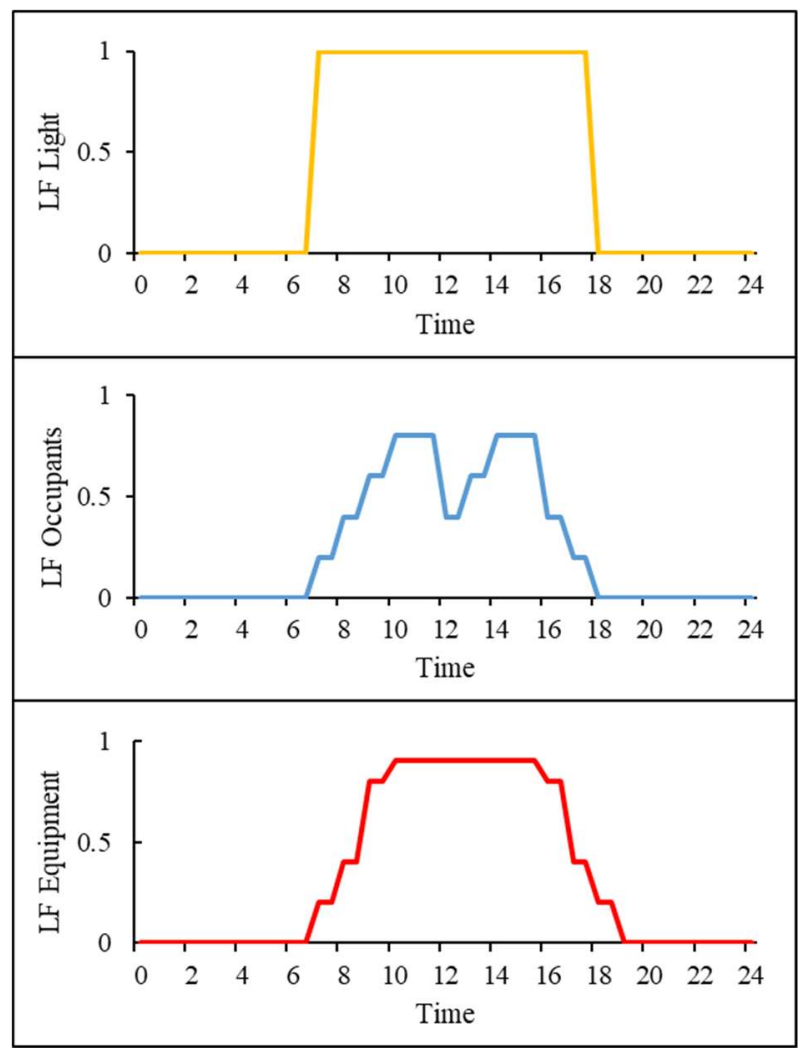

Figure 1: Time schedules for internal loads; lighting (yellow), occupation (blue) and equipment (red) as LF.

\section{Locations}

Different climate data sets ensure the consideration of external loads in the simulations. Each climate data set includes hourly values of ambient temperature $\left(T_{a m b}\right)$, relative air moisture $(\phi)$, direct normal and diffuse radiation, wind velocity and cloudiness for a period of one year. The source of the climate data set is the ASHRAE IWEC2 database. Table 2 presents yearly average values of $T_{a m b}$ and $\phi$ as well as the latitude of the respective locations. 
Table 2: Climate data of the modelled locations (Palermo, Zurich, Stockholm).

\begin{tabular}{|c|c|c|c|}
\hline Location & Latitude & $\begin{array}{c}\mathbf{T}_{\text {amb }} \\
{\left[{ }^{\circ} \mathbf{C}\right]}\end{array}$ & $\begin{array}{c}\text { Rel. humidity } \\
\boldsymbol{\phi}[\mathbf{\%}]\end{array}$ \\
\hline Palermo (IT) & $38.183 \mathrm{~N}$ & 18.9 & 73.1 \\
\hline Zurich (CH) & $47.383 \mathrm{~N}$ & 9.5 & 76.3 \\
\hline Stockholm (SE) & $59.65 \mathrm{~N}$ & 6.7 & 80.3 \\
\hline
\end{tabular}

The use of different locations is relevant to consider the impact of differing climate conditions on cooling load. Besides the differentiation in latitudes, cities with continental and maritime climate were chosen for the study. Palermo as a hot and Mediterranean city, Zurich with continental climate and Stockholm as northern city with cold winters and pleasantly warm summers satisfy a wide range of climate conditions.

\section{Cooling strategies}

To model different cooling strategies, zone temperature profiles were defined. The minimum zone temperature setpoint was defined at $21^{\circ} \mathrm{C}$ (cf. Figure 2, black solid line) in all buildings to maintain reasonable comfort conditions under all circumstances. Additionally, three different cooling strategies were defined, differentiated by maximum allowed temperature for weekday time schedules (illustrated in Figure 2).

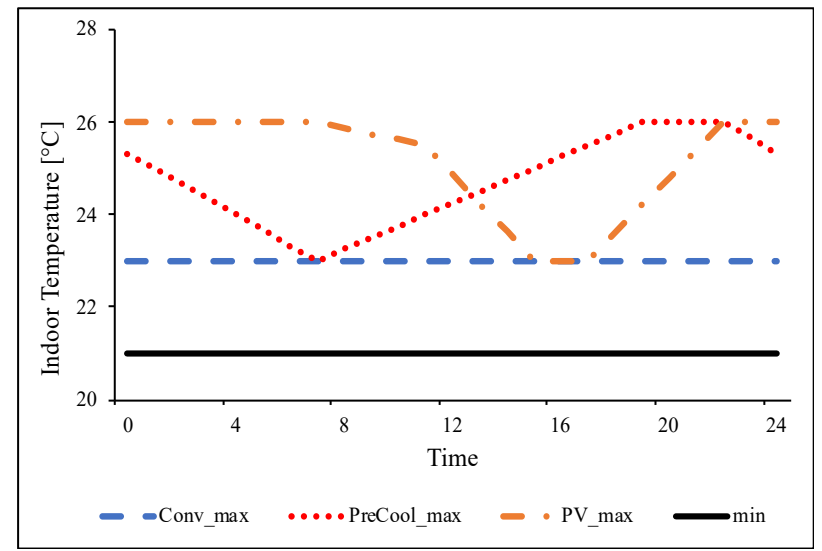

Figure 2: Considered time schedules of cooling strategies (CONV, PreCool and PV_S), maximum- (max) and minimum temperature setpoint (min).

As reference, a conventional strategy (CONV) with a constant upper setpoint temperature was defined (1). Second, a precooling strategy ( $\mathrm{PreCool}$ ) with the goal to shift the cooling load from peak load to off-peak load hours (2) in the early morning was defined (2). Third, a photovoltaic strategy was defined $(P V S S)$, where especially the solar intensive hours of the day ought to be used to satisfy the daily cooling loads (3). Depending on the cooling strategy, the maximum zone temperature setpoint was adjusted:

(1) CONV: Conventional cooling strategy (Figure 2, blue dashed line) with a constant upper setpoint of conv_max $23^{\circ} \mathrm{C}$ (this strategy represents the current practice for chillers).

(2) PreCool: Precooling strategy (Figure 2, red dotted line) where the zone temperature PreCool max during the day is allowed to linearly increase from $23^{\circ} \mathrm{C}$ (7 a.m.) to $26^{\circ} \mathrm{C}$ ( 7 p.m.), depending on the internal and external heat loads. From 7 p.m. to $10 \mathrm{p} . \mathrm{m}$. the maximum indoor temperature is kept at $26^{\circ} \mathrm{C}$ (no freecooling considered). Next, indoor temperature is linearly reduced from $26^{\circ} \mathrm{C}$ at 10 p.m. to $23^{\circ} \mathrm{C}$ at 7 a.m. resulting in increasing cooling load.

(3) PV_S: Optimized photovoltaic strategy (Figure 2, orange dash-dotted line). From 7 a.m. on, the zones are cooled down by utilizing PV power to $25.4^{\circ} \mathrm{C}$ at 11 a.m. From 11 a.m. to 3 p.m., the temperature is reduced to $23^{\circ} \mathrm{C}$. Afterwards, the temperature is maintained at $23^{\circ} \mathrm{C}$ until 5 p.m. From 5 p.m. to $10 \mathrm{p} . \mathrm{m}$. the temperature can linearly increase to $26^{\circ} \mathrm{C}$ where it is maintained until midnight (PV_max).

During weekend hours, the maximum indoor temperature was allowed to exceed the maximum zone temperature setpoints, depending on the external load impact.

IDA-ICE simulations were run for all three cooling strategies and three building types at the three different geographic locations.

\section{Load calculations}

Thermal cooling loads $P_{t h}$ were converted to electrical loads $P_{e l}$ by applying a dynamic coefficient of performance (COP). Hence, all following cooling load results presented in this work refer to the electrical load. The COP was calculated using the evaporator temperature $T_{e}$ and the condenser temperature $T_{C}$ (cf. equation (1)) which was considered as a function of ambient temperature. The correction factor $v$ (degree of quality) was assumed as 0.35 and allows the conversion from the theoretical COP to the real COP.

$$
C O P=v \cdot \frac{T_{e}}{T_{c}-T_{e}}
$$

For ambient temperatures $>10^{\circ} \mathrm{C}$, the conversion to electrical energy was calculated using equation (2), whereby $A E F \cdot P_{t h}$ represents the auxiliary energy needed for extra appliances (e.g. pumps, fans). The auxiliary energy factor (AEF) was assumed to be $4.5 \%$.

$$
P_{e l}=\frac{P_{t h}}{C O P}+A E F \cdot P_{t h}
$$

For ambient temperatures $<10^{\circ} \mathrm{C}$ it was assumed, that the cooling machine is powered off and the electricty load therefore only consists of the auxiliary energy (second term in equation (2)).

\section{Analysis}

The 3-day periods with the highest outside temperatures of the simulation year were identified for each location to study the load profiles and illustrate the maximum LS potential. Additionally, several daily time intervals were analysed for the period of one year to evaluate different potentials of the cooling strategies defined. Focus of this analysis was put on the peak hours in the late afternoon $\&$ evening, and for early morning hours to determine the freecooling potential and for noon and afternoon hours to determine the PV electricity potential (cf. Table 3 ). 
Table 3: Analysed time periods during the day for a yearly period and reason for the chosen time period.

\begin{tabular}{|c|c|}
\hline Time interval & Reason of evaluation \\
\hline 4 p.m. to 8 p.m. & LS potential in peak hours \\
\hline 3 a.m. to 7 a.m. & $\begin{array}{c}\text { Free cooling potential in early } \\
\text { morning hours }\end{array}$ \\
\hline 12 a.m. to 4 p.m. & PV electricity use during sun hours \\
\hline 0 a.m. to 12 p.m. & $\begin{array}{c}\text { Potential of cooling energy reduction } \\
\text { over whole year }\end{array}$ \\
\hline
\end{tabular}

\section{Results \& Discussion}

For a first evaluation of the LS potential, the last day of the 3-day period with highest outside temperatures of the year at each corresponding location (cf. Table 4) was chosen. This day represents hot summer days with a high expected cooling load and reduces the impact of preconditions regarding the temperature level of the building mass. In Palermo the ambient temperature does not drop below $26^{\circ} \mathrm{C}$ on this particular day, not even during night time. Especially in the BN1 building, cooling is required during $24 \mathrm{~h}$. In Stockholm and Zurich, maximum temperatures of $27.2^{\circ} \mathrm{C}$ and $31.4^{\circ} \mathrm{C}$ are measured. During night, temperatures in both cities drop below $19^{\circ} \mathrm{C}$ and no perpetual cooling load is required.

Table 4: Date and 24 h average ambient temperature of a typical hot day at each location.

\begin{tabular}{|c|c|c|}
\hline Location & Date & $\mathbf{T}_{\mathbf{a m b}}{ }^{\circ} \mathbf{C} \mathbf{]}$ \\
\hline Palermo (IT) & $10^{\text {th }}$ of August & 31.4 \\
\hline Zurich $(\mathrm{CH})$ & $4^{\text {th }}$ of August & 25.0 \\
\hline Stockholm $(\mathrm{SE})$ & $4^{\text {th }}$ of August & 22.9 \\
\hline
\end{tabular}

\section{Impact of building type}

For the specified days (cf. Table 4), the plots in Figure 3 illustrate the cooling load curves and the ambient temperature for all three locations (Palermo, Stockholm, Zurich) and the three building types (BN1, BN2 and BB3) under the given set of LS strategies. As expected, the building type has a high impact on the magnitude and the load profile (shape of the curve). In particular, buildings with a high building mass such as BB3 but
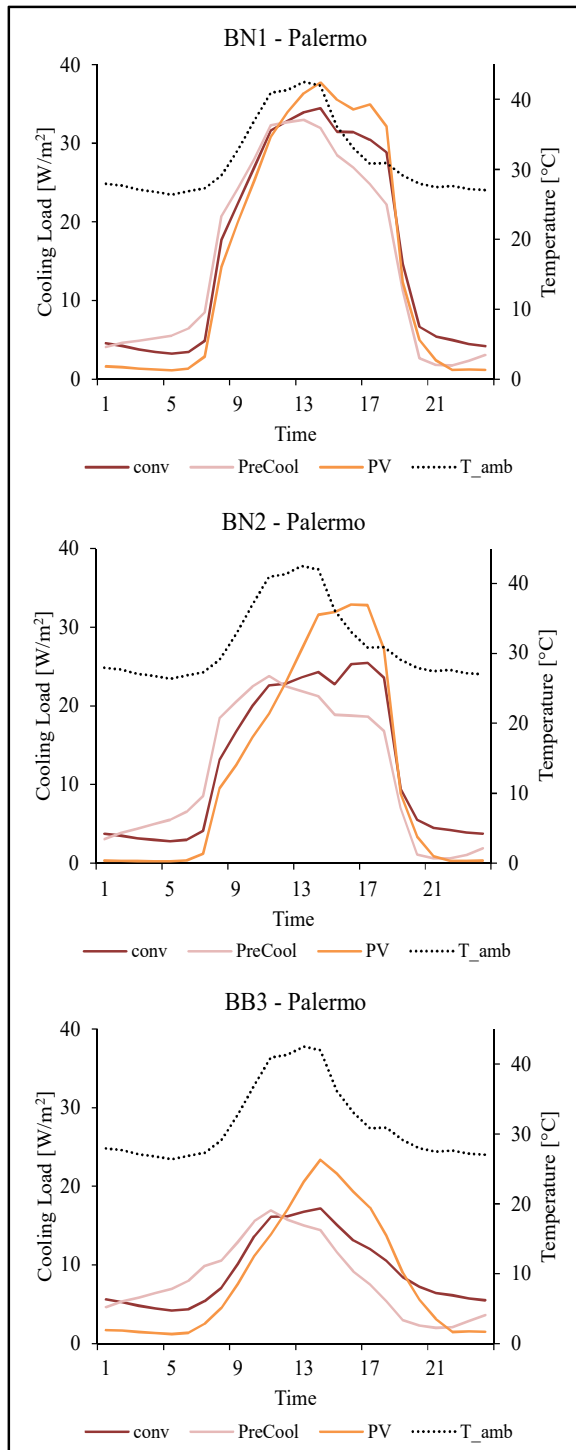
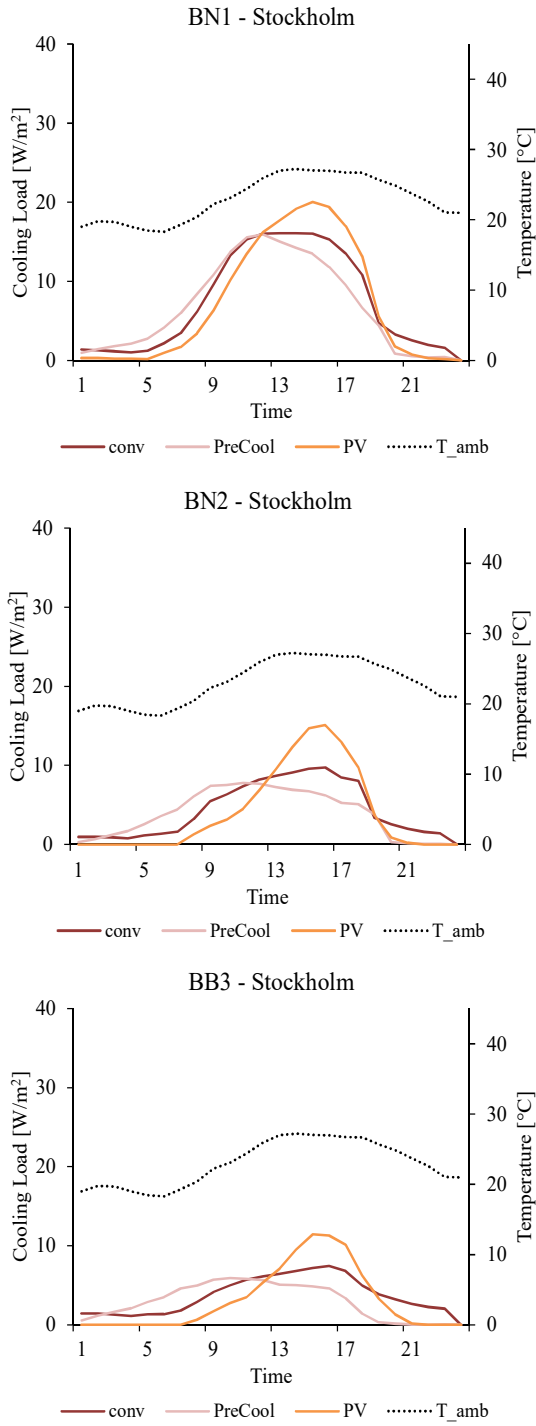

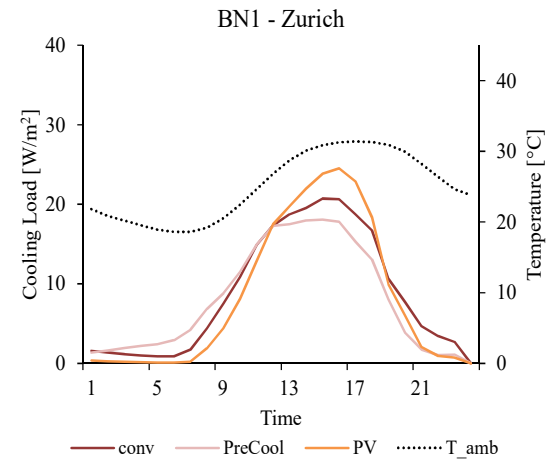

BN2 - Zurich
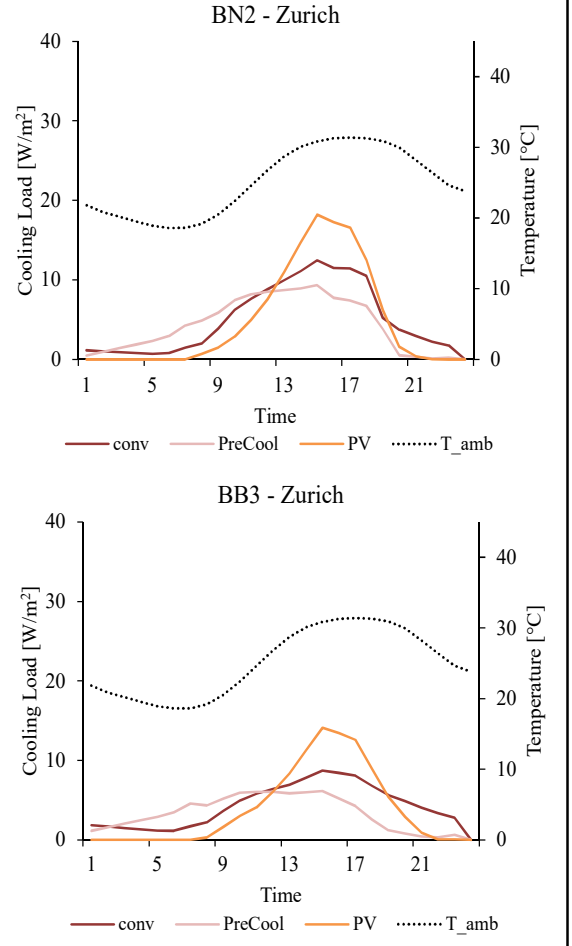

Figure 3: Comparison of different cooling strategies in different building types (BN1, BN2, BB3) at differing locations (Palermo, Stockholm, Zurich) for the third day in the hottest 3-day period of the year. 
also building BN2 have a lower peak load demand compared to the BN1 building. For Palermo, the peak load of the $P V S$ strategy (cf. Figure 3, orange line) in the BB3 building is $23.4 \mathrm{~W} / \mathrm{m}^{2}$ compared to $37.7 \mathrm{~W} / \mathrm{m}^{2}$ in the BN1 building (-38\%). For the PreCool strategy, the difference is even higher with $16.9 \mathrm{~W} / \mathrm{m}^{2}$ for the BB3 compared to $33.0 \mathrm{~W} / \mathrm{m}^{2}$ for the BN1 (-49\%), using the building mass effectively for cooling purposes. In Zurich and Stockholm, the peak cooling load is as well lower in the BB3 and BN2 buildings compared to the BN1 building for the $P V S$ strategy $(-42 \%$ and $-43 \%$, resp.) whereas in the case of the PreCool strategy the peak load is slightly lower (-66\% and $-63 \%$ for BB3 and $\mathrm{BN} 2$, resp.). For the $C O N V$ strategy, similar lower peak load hours are observed for that day.

Given the building typology, the solar load due to the higher window share is the most significant factor for the increased cooling load in BN1-type buildings. In Palermo, the solar driven cooling load over this particular day is more than double for BN1 compared to BB3.

Additionally, the thermal capacity of the building walls, which absorb heat in the hot afternoon hours, lower the cooling demand in BB3. The results of the different building types reveal that supplementary to the peak loads, the total cooling loads are altered.

This context has to be kept in mind when designing building performance standards and requirements, as it is expected that cooling demand will increase in the future due to higher outdoor temperatures.

\section{Impact of cooling strategy}

Comparing the PreCool strategy with the CONV strategy, one can observe two main effects on the PreCool load curve:

(1) a horizontal shift of the load curve towards earlier hours with a slightly increased cooling load between 1:00 and 5:00 (LS potential; cf. Figure 3)

(2) a reduced cooling load in the afternoon hours between 13:00 and 19:00.

The time shift is mainly driven by the need to reduce room temperature in the early morning hours to reach the set-point of $23 \mathrm{C}$ at eight o'clock in the morning, whereas the reduced cooling demand is the consequence of higher indoor temperatures in the afternoon.

Although, the load curve can be shifted in time by the precooling strategy, the peak load of the day is only slightly reduced. This is explained by the high cooling demand on that particular day, which is illustrated in the BN1-Palermo plots. Since the temperature rises to high levels in the afternoon hours and the cooling storage is limited, maximum cooling loads for all strategies are in a similar range. In Stockholm and Zurich, the peak demand in the PreCool strategy is as well only slightly lower following the drivers of temperature increase, building mass and window losses (U-values). On other summer days, where the required cooling load is reduced due to lower outside temperatures, the peak load reduction for the precooling strategy is more distinct.

\section{LS potential}

The LS potential can be derived for the three different locations and is depicted for the PreCool strategy compared to the $C O N V$ strategy for a $\mathrm{BB} 3$ building in Palermo (Figure 4).

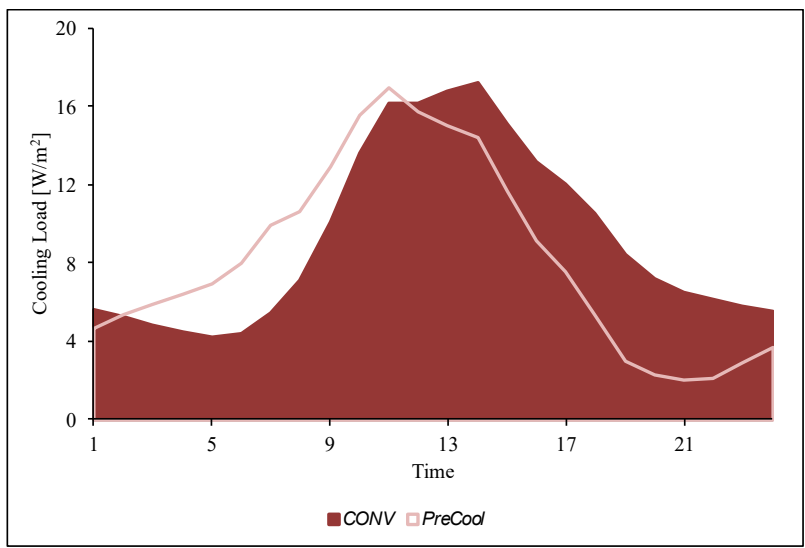

Figure 4: Cooling load of CONV and PreCool strategy on the 10th of August for a BB3 building in Palermo.

From 11 a.m. to 12 p.m., the cooling demand of the PreCool strategy is lower compared to the CONV strategy. The dark red area between the two cooling load curves represents the reduced energy demand during that period, from which only a fraction of approx. 50\% (light red area) is shifted to the period between 2 a.m. and 11 a.m. (area with no overlap).

Similar to the evaluation of the hot summer day in Figure 3, the potential to shift cooling loads by the PreCool strategy from peak to off-peak hours is evaluated. Therefore, the cooling energy demand between the peak load hours 4 p.m. to 8 p.m. is calculated (cf. Table 5). Results reveal that, the colder the climate, the higher the relative reduction in cooling energy during peak load hours. Table 5 also shows the increased cooling energy reduction during peak load hours by means of massive buildings.

Table 5: Electricity demand for cooling energy of CONV and PreCool strategies between 4 and 8 p.m. on a hot summer day in 3 different building types and locations.

\begin{tabular}{|c|c|c|c|c|c|c|}
\hline & \multicolumn{2}{|c|}{ Palermo } & \multicolumn{2}{|c|}{ Stockholm } & \multicolumn{2}{|c|}{ Zurich } \\
\hline & 㐋 & 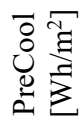 & 㐋 & 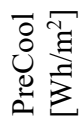 & 劳 & 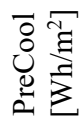 \\
\hline BB3 & 38.2 & 18.2 & 19.0 & 5.4 & 25.4 & 8.7 \\
\hline $\mathrm{BN} 2$ & 64.1 & 43.5 & 22.4 & 14.4 & 30.9 & 18.5 \\
\hline $\mathrm{BN} 1$ & 80.6 & 60.9 & 32.4 & 21.5 & 53.7 & 40.3 \\
\hline
\end{tabular}

The LS potential to shift cooling loads by the $P V S$ strategy into the sun-rich hours is evaluated for the hot summer day of Figure 3. Therefore, the cooling energy demand between the sun-rich hours from 12 o'clock noon to 4 p.m. is calculated (cf. Table 6). Especially the massive buildings show a higher potential to shift cooling loads to the sunny hours of the day. 
Table 6: Electricity demand for cooling of CONV and

PV_S strategies between 12 noon to 4 p.m. on a hot summer day for 3 building types, at 3 different locations.

\begin{tabular}{|c|c|c|c|c|c|c|}
\hline & \multicolumn{2}{|c|}{ Palermo } & \multicolumn{2}{|c|}{ Stockholm } & \multicolumn{2}{|c|}{ Zurich } \\
\hline & 龸范 & 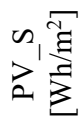 & 点 & 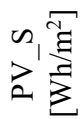 & ${ }_{0}^{3}{ }_{0}^{\pi}$ & 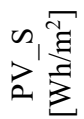 \\
\hline BB3 & 62.2 & 85.0 & 28.0 & 39.4 & 31.9 & 47.2 \\
\hline $\mathrm{BN} 2$ & 96.0 & 123.6 & 37.1 & 51.7 & 45.1 & 61.1 \\
\hline BN1 & 131.2 & 143.9 & 63.5 & 76.3 & 79.6 & 90.1 \\
\hline
\end{tabular}

The LS potential is also demonstrated if the shifted cooling energy is calculated within a period of time as a function of daily averaged ambient temperatures (cf. Figure 5). All curves include data from the whole year period in Palermo. The dotted lines represent the cooling energy shifted into the sunny hours (12 a.m. to 4 p.m.) by the PV_S strategy compared to the CONV strategy. The solid lines represent the cooling energy shifted away from peak load hours (4 to 8 p.m.) by the PreCool strategy compared to the CONV strategy.

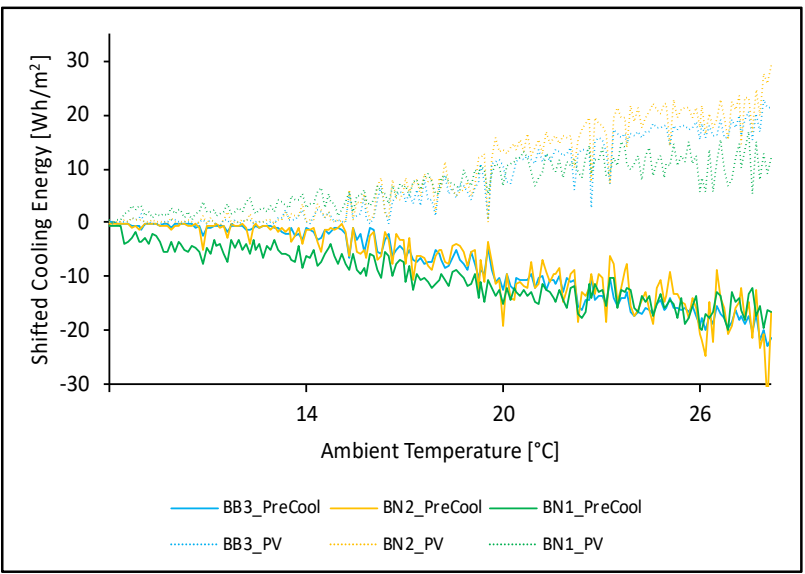

Figure 5: Saved elec. for cooling in 3 building types (BN1, BN2, BB3) by the PreCool strategy (from 4 p.m. to 8 p.m.) and the PV_S strategy (from noon to 4 p.m.), both compared with the CONV strategy in Palermo.

The goal of the $P V \_S$ strategy is to increase the cooling load during 12 a.m. and 4 p.m. when potential grid connected solar electricity generation and specific building related heating demand is highest. Hence, the shifted cooling energy compared to the conventional strategy is a positive impact.

Since the goal of the PreCool strategy is to shift the cooling energy away from peak hours, the shifted cooling energy is a negative number. The shifted cooling energy shows an increasing trend for the $P V \_S$ strategy and a decreasing trend for the PreCool strategy. Similar results are obtained for Zurich and Stockholm (not illustrated here), with the only difference that these locations have more days with lower ambient temp. and a corresponding lower cooling demand.

\section{Evaluation of energy efficiency potential during high} cooling load hours (4 p.m. to 8 p.m.)

To quantify the efficiency potential of the different LS strategies, the 3-days results shown in Figure 3 are analysed for the whole year. Assuming highest saving potentials in the time interval between 4 and 8 p.m., the total specific cooling energy considerably decreases in that period, thus indicating the LS potential of the PreCool strategy (Figure 6). The shifted cooling energy with this strategy between 4 and 8 p.m. varied between $31 \%$ (BN1 in IT) and $75 \%$ (BB3 in SE) in comparison to the $C O N V$ strategy. Independent of the building type, reasonable cooling loads can be shifted. Although, the relative shifted amount is higher in colder climates (SE and $\mathrm{CH}$ ), absolute values in Palermo are still promising.

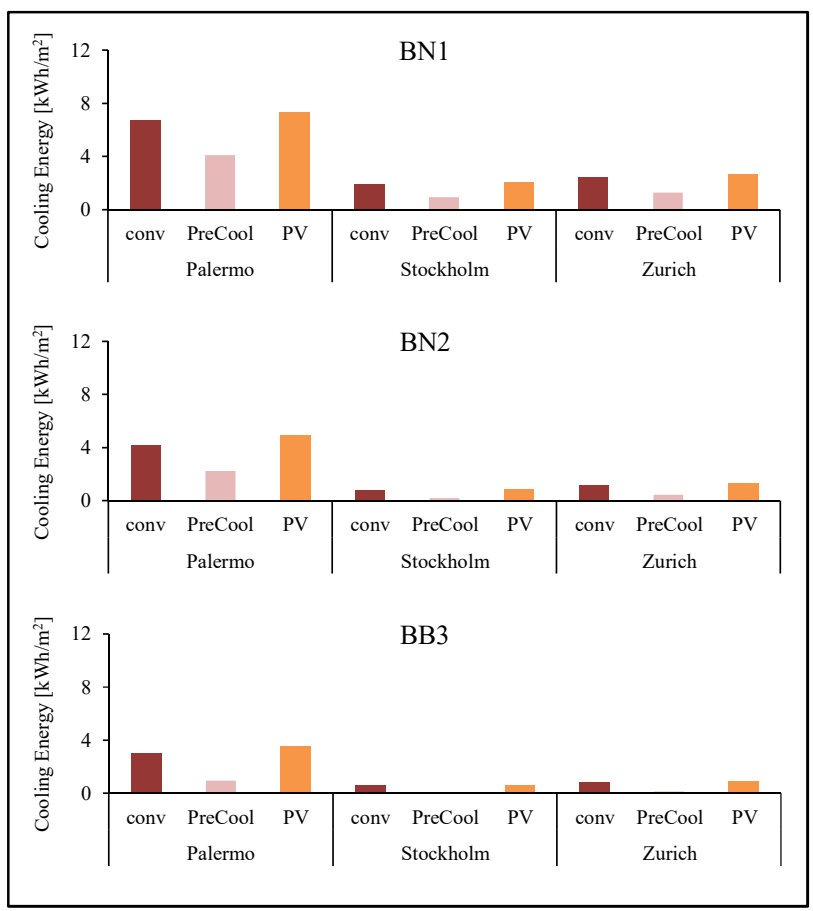

Figure 6: Yearly specific cooling energy between 4 p.m. and 8 p.m. for 3 LS strategies, buildings and locations.

In the $P V \_S$ strategy, the maximum cooling load occurs during the day period 4 p.m. to 8 p.m. and offers reasonable potentials to solar electricity on site. Again, higher thermal mass and lower window share were crucial in reducing peak energy demand.

\section{Evaluation of free cooling potential}

Besides shifting peak loads (cf. PreCool strategy in Figure 6), it is important to monitor where the cooling loads are shifted. At all three locations, the annual hourly average temperatures are lowest before 7 a.m. Considering the PreCool strategy, high shares of the cooling demand are used during early morning hours between 3 a.m. and 7 a.m., as demonstrated in Figure 7, with the highest loads for the PreCool strategy. This load shift is beneficial in two ways:

(1) Electricity costs can be reduced when running chillers during hours with low tariffs (assumed under current electricity pricing schemes) and lower ambient temperatures for better COP.

(2) Free cooling through heat exchangers or mech. ventilation can be used when outside temperatures are below $23^{\circ} \mathrm{C}$, offering additional savings potential. 
Free cooling as an energy efficiency strategy is usually differentiated into airside and waterside free cooling. With low ambient temperatures as e.g. in $\mathrm{CH}$ specially during the intermediate season, the ambient air can directly remove heat load from inside the buildings. Oró, Depoorter, Pflugradt, \& Salom (2015) evaluated the free cooling potential combined with thermal energy storage in five different European cities including Stockholm. They showed that Stockholm had the highest free cooling potential using outside air with more than 7000 operation hours yearly. However, besides reducing cooling demand, changes in investment and operation costs (e.g. for fans and humidifiers) need to be considered for a cost-effectiveness analysis (Oró et al., 2015). While the cooling energy in Figure 7 varies along the different cooling strategies, the influence of the building type does not appear high. Especially for IT, the night free cooling potential is in similar range for all building types.

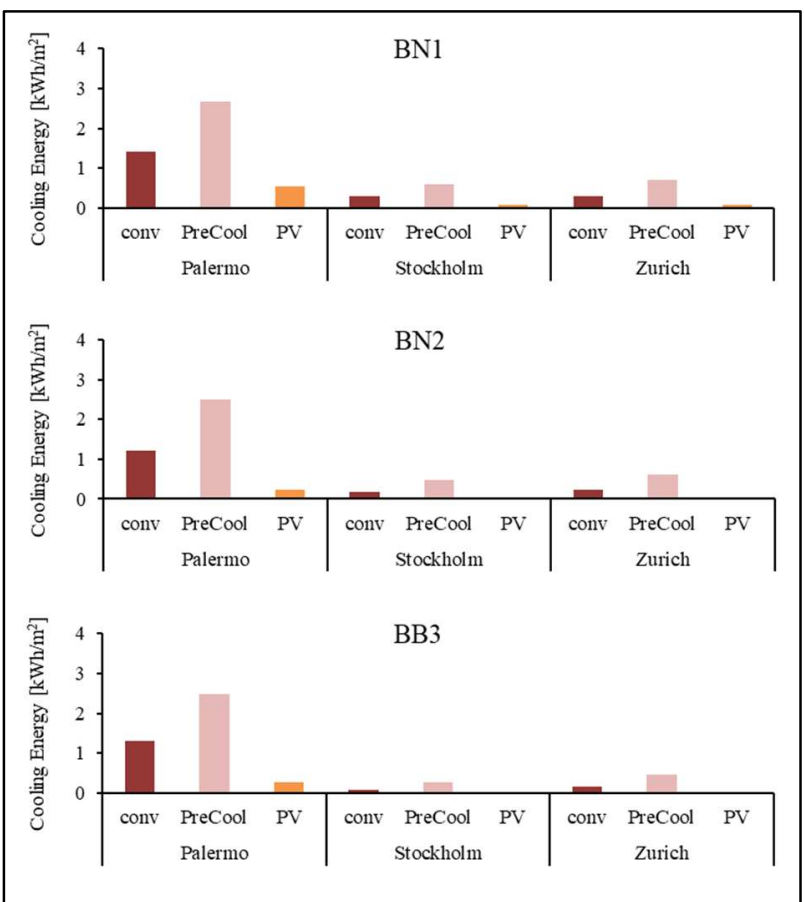

Figure 7: Yearly specific cooling energy between 3 and 7 a.m. for 3 LS strategies, buildings and locations.

\section{Evaluation of $\boldsymbol{P} V_{-} \boldsymbol{S}$ potential}

The period between 12 noon and 4 p.m. is chosen to evaluate the PV_S cooling strategy, because the direct and diffuse radiation is highest during this period. However, the cooling energy of the PV_S strategy only slightly exceeds the cooling energy of the CONV strategy for this period (Figure 8). Absorbed heat by thermal mass and lower solar heat gains during the day are more distinct in the heavy mass buildings BN2 and BB3. Despite the high cooling load which can be achieved by the PV_S strategy during daytime, some cooling loads are still required until 9 or 10 p.m. (especially in hot summer days in IT), when solar electricity generation is already low or even zero. In addition, limited sun hours in more northern countries such $\mathrm{CH}$ and $\mathrm{SE}$ in the summer further aggravate the problem. Shifting more cooling load to hours earlier in the morning with PV_S does not allow to fully cover load by solar electricity as during these hours lower radiation reduced solar electricity generation.

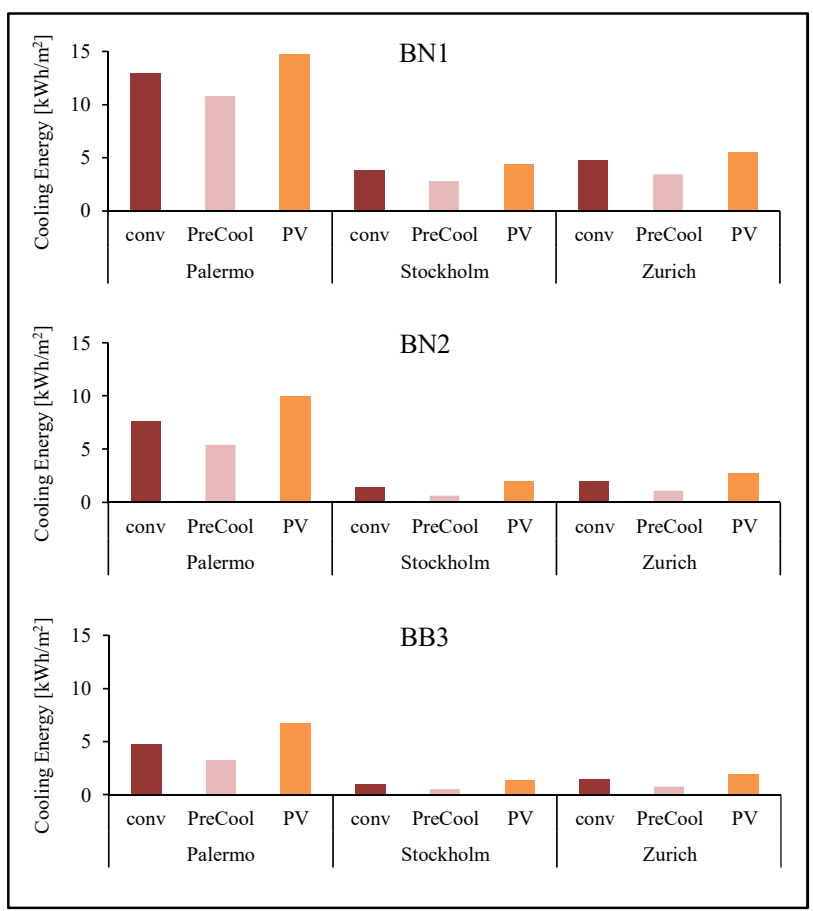

Figure 8: Yearly specific cooling energy between noon and 4 p.m. for 3 LS strategies, buildings and locations.

\section{Evaluation of total cooling energy demand}

Besides the LS potential, the different cooling strategies show potential to decrease the overall cooling demand per day compared to $C O N V$ strategies (Figure 9).

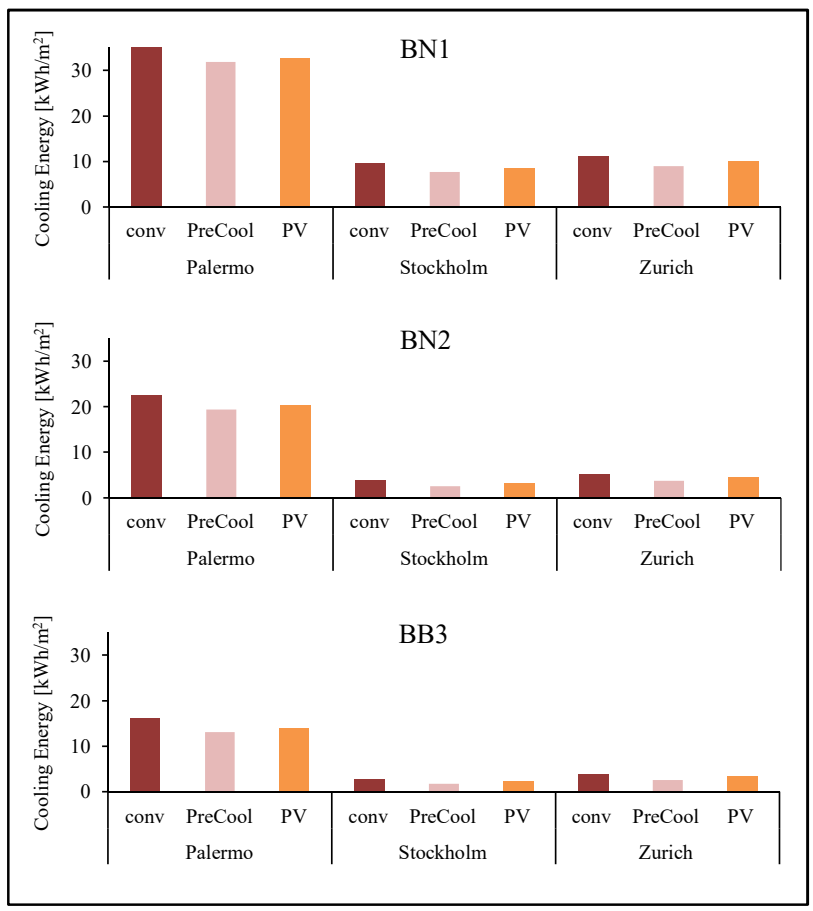

Figure 9: Yearly specific cooling energy for 3 LS strategies, building types and locations. 
Depending on location and building type, the specific cooling energy can be reduced between $8 \%$ and $35 \%$ by means of the cooling strategies PreCool and PV S. One driver for these results is the higher maximum temperature setpoints of the PreCool and $\mathrm{PV} S$ strategies.

\section{Conclusion \& Outlook}

This study shows the potential of shifting cooling loads from peak to off-peak hours by means of precooling the building thermal mass. The simulations were run for three different building types at three locations with differing climate conditions. By analysing different daily time spans, we show the advantages of such measures. Further, by a second cooling strategy, the cooling potential using solar electricity by shifting a large amount of cooling energy to noon and afternoon hours was assessed. The $P V \_S$ strategy shows the potential to shift a high amount of the cooling load into the sun rich hours in the afternoon and make use of photovoltaic electricity by complying with defined comfort conditions. This strategy is especially promising for sunrich locations in the Mediterranean regions.

Both cooling strategies were compared to a conventional cooling strategy with constant temperature setpoints which are often used as standard set-up for air conditioning in office buildings.

Besides shifting cooling loads, both strategies offer savings potentials to decrease the overall yearly cooling energy compared to the $C O N V$ strategy.

Our results are extending previous studies, and the simulation results show that by precooling, a significant amount of cooling energy is shifted from peak to offpeak hours at all three locations. Results for massive buildings confirm the role of thermal mass to shift cooling loads. However, despite the benefit of cooling buildings in hot summer days, thermal mass can entail drawbacks especially in cold climates with high heating demands (Reilly \& Kinnane, 2017). Hence, a continuation of this study by analysing heating loads in winter would give such insights. Additionally, we did not include electricity price information which is indirectly reflecting the effective need for LS each day of the year.

However, the results for single buildings from this study will be further integrated into energy system models within the REFLEX project (TU Dresden, 2016). Especially in the cooling sector, coupling of building simulation results to energy system models and the evaluation of the overall potential for DSM options including respective price signals will be beneficial.

\section{Acknowledgement}

This publication, was prepared in the context of the project REFLEX and has received funding from the EU's Horizon 2020 research and innovation program under grant agreement No 691685 and the Swiss State Secretary for Education, Research and Innovation (SERI).

\section{References}

Amusat, O. O., Shearing, P. R., \& Fraga, E. S. (2018). Optimal design of hybrid energy systems incorporating stochastic renewable resources fluctuations. Journal of Energy Storage, 15, 379399.

Connolly, D. (2017). Heat Roadmap Europe: Quantitative comparison between the electricity, heating, and cooling sectors for different European countries. Energy, 139, 580-593.

Cui, B., Wang, S., Yan, C., \& Xue, X. (2015). Evaluation of a fast power demand response strategy using active and passive building cold storages for smart grid applications. Energy Conversion and Management, 102, 227-238.

German, A., Hoeschele, M., Springer, D., \& Others. (2014). Maximizing the Benefits of Residential PreCooling. ACEEE Summer Study Energy Effic. Build. Pacific Grove: California.

Jakob, M., Kallio, S., \& Bossmann, T. (2014). Generating electricity demand-side load profiles of the tertiary sector for selected European countries. In Proceedings of 8th International Conference Improving Energy Efficiency in Commercial Buildings (IEECB 14).

Ma, J., Qin, J., Salsbury, T., \& Xu, P. (2012). Demand reduction in building energy systems based on economic model predictive control. Chemical Engineering Science, 67(1), 92-100.

Oró, E., Depoorter, V., Pflugradt, N., \& Salom, J. (2015). Overview of direct air free cooling and thermal energy storage potential energy savings in data centres. Applied Thermal Engineering, 85, 100110.

Reilly, A., \& Kinnane, O. (2017). The impact of thermal mass on building energy consumption. Applied Energy, 198, 108-121.

Rongxin, Y. (2015). Use of Thermal Mass in Building Energy Storage. In Handbook of Clean Energy Systems (pp. 1-15). American Cancer Society.

TU Dresden. (2016). REFLEX project. Retrieved January 7, 2019, from http://www.reflex-project.eu

Turner, W. J. N., Walker, I. S., \& Roux, J. (2015). Peak load reductions: Electric load shifting with mechanical pre-cooling of residential buildings with low thermal mass. Energy, 82, 1057-1067.

Xu, P., Haves, P., Piette, M. A., \& Braun, J. (2004). Peak demand reduction from pre-cooling with zone temperature reset in an office building. (No. LBNL55800). Lawrence Berkeley National Lab. (LBNL), Berkeley, CA (Unites States).

Yang, L., \& Li, Y. (2008). Cooling load reduction by using thermal mass and night ventilation. Energy and Buildings, 40(11), 2052-2058. 